\title{
Compressive Strength of Jordanian Cement Mortars
}

\author{
Hamadallah Al-Baijat ${ }^{1}$, Maria Chiara Bignozzi ${ }^{2}$, Basem K. Mohd ${ }^{1}$ \\ ${ }^{1}$ College of Engineering, Civil Engineering Department, Tafilah Technical University, Tafilah, Jordan \\ ${ }^{2}$ University of Bologna, Bologna, Italy \\ Email: albaijath@yahoo.com
}

Received January 27, 2013; revised February 25, 2013; accepted March 8, 2013

\begin{abstract}
Mortars have been prepared from six cement Jordanian brands and tested for their compressive strengths at 2, 7 and 28 days. The strength has been related to some physical parameters. It has been concluded that the compressive strength and its development with age has some variations between the different cement brands. There is an inverse linear relationship between compressive strength and water absorption, and a weaker positive relation with density. There is no clear relation between consistency and compressive strength. Inverse linear relations exist between less than 63 microns size fraction and strength. To account for the differences in compressive strength at different ages and using different cement brands, it is very important to identify the type and amount of cement mineral phases using concrete petrography and X-ray diffraction and fluorescence techniques.
\end{abstract}

Keywords: Natural Asset; Financial Value; Neural Network

\section{Introduction}

According to ASTM C150 [1], Portland cement is defined as hydraulic cement produced by pulverizing clinker primarily consisting of hydraulic calcium silicates, and containing one or more types of calcium sulfate as an interground addition. "Blended cement" refers other materials which may be added or blended in the production of hydraulic cement. ASTM C 1157 [2] uses the term for a hydraulic cement consisting of Portland cement and other appropriate inorganic materials

There are four major compounds constituting Portland cement: tricalcium silicates $(\mathrm{C} 3 \mathrm{~S})$, dicalcium silicates $(\mathrm{C} 2 \mathrm{~S})$, tricalcium aluminate $(\mathrm{C} 3 \mathrm{~A})$, and tetracalcium aluminoferrite (C4AF). Shortened names are used by cement chemists each letter describes one oxide: $\mathrm{C}=$ $\mathrm{CaO} ; \mathrm{S}=\mathrm{SiO}_{2} ; \mathrm{A}=\mathrm{Al}_{2} \mathrm{O}_{3} ;$ and $\mathrm{F}=\mathrm{Fe}_{2} \mathrm{O}_{3}$. According to ACI 225R-99 [3], five types of Portland cement are categorized for different applications, and the properties of each cement type are controlled by the limiting contents of the four compounds. The two calcium silicate compounds (C3S and $\mathrm{C} 2 \mathrm{~S}$ ), are the main phases and make up $75-80$ percent of the Portland cement. The quantity of C3A significantly influences the early reactions and later durability of the cement paste, and accounts for the main difference between Type II and Type III cement. Mortars (Frohnsdorff, 1990) [4] are mixtures of cements with sand, or other fine aggregate, and water. The sand-cement ratio is usually around 3. Mortars are used extensively in masonry construction as the bedding materials for the masonry units and as a rendering applied to vertical surfaces for architectural purposes or to improve water tightness

Quality assurance testing of cements for strength and dimensional stability is usually carried out on standard mortars made with standard quartz sand. As mechanical strength of hardened cement is the most important property of the material required for structural use, strength properties are required by all specifications for cement. According to Neville (1993) [5], the strength of mortar depends on the cohesion of the cement paste and on its adhesion to the fine aggregate (quartz sand in our case). In the compressive strength mortar test a 1:3 cementsand mortar is used. The cement, which is used in construction works, must have certain qualities in order for it to play its part actively; otherwise it will create a number of problems. When these properties lie within a certain specified range of standards, the engineer is confident that the cement performance will be quite satisfactory. Moreover, based on these properties, it is possible to compare the quality of cement from different sources. A number of tests are performed in the laboratories of cement industries to ensure that the cement complies with the desired quality and meets the requirements of the relevant standards (Miller and Conway, 2003 [6]; Noor ul-Amin, 2010 [7]). There are several brands of OPC available in the local market of Jordan, whose chemical ingredients are the same, but variations in their physical parameters occur due to the variation in the amount of chemical constituencies. This study aims at investigating 
some physical parameters affecting the compressive strength of selected Jordanian cement mortars. It was found that compressive strength increases with both water absorption and the percentage of fine grain size and increases with density.

\section{Materials and Methods}

Samples of cement (two kg of each) were shipped to Italy for investigation. The senior author conducted the following tests at the laboratories of University of Bologna, Italy during the summer of 2012. The proportion of the mix was: water $=225 \mathrm{~g}$, cement $450 \mathrm{~g}$ and $2 \mathrm{~mm}$ sand $1350 \mathrm{~g}$. All tests were carried out according to European Standard EN 196-, 2005 [8]. Fineness measures the amount of cement that passes through the two consequent 0.125 and $0.063 \mathrm{~mm}$ sieves when using $100 \mathrm{~g}$ of cement. The sieving continued for fifteen minutes and was carried out using an electro-mechanical shaker. The fineness expressed as a numerical value is the part that accumulates on the pan.

Consistency or flow of fresh cement was measured using a mold $(7 \mathrm{~cm}$ top diameter, $10 \mathrm{~cm}$ bottom diameter and $6 \mathrm{~cm}$ height) which was filled in two layers (each compacted with 15 blows to make the sample as circular as possible) and the average diameter was measured in two perpendicular directions of the sample. This test, named flow test, was covered by ASTM Standard C12439.

Consistency or flow was determined using the following formula:

$$
\text { Consistency }=\left[\left(d_{a}-10\right) / 10\right] \times 100 .
$$

where $d_{a}=$ average diameter of the fresh concrete sample Compressive strength test method comprises the determination of the compressive strength of prismatic cement mortar test specimens $400 \mathrm{~mm} \times 400 \mathrm{~mm} \times 16 \mathrm{~mm}$ in size. These specimens are cast from a batch of plastic mortar containing one part by mass of cement, 3 parts by mass of CEN standard sand and one half part of water (water/cement ratio 0.50). The mortar is prepared by mechanical mixing and is compacted in a mould using a jolting apparatus. The specimens are stored in the mould in a moist atmosphere for 24 hours and, after demoulding, specimens are stored under water until strength testing. At the required age (3, 7 and 28 days), the specimens were taken from their wet storage and broken into two halves using suitable means which do not subject the prism halves to harmful stresses, and each half to harmful stresses, and each half tested for strength in compression. The testing machine for the determination of compressive strength has an accuracy of $\pm 1 \%$ of the recorded load in the upper four-fifths of the range being used when verified in accordance with EN ISO 7500-1. A rate of load increase of $2400 \pm 200 \mathrm{~N} / \mathrm{s}$ is provided with the instrument fitted with an indicating device so constructed that the value indicated at failure of the specimen is unloaded which is achieved by the use of a maximum on a pressure gauge or a memory on a digital display. The vertical axis of the ram coincides with the vertical axis of the machine and during loading the direction of movement of the ram was along the vertical axis of the machine, furthermore, the resultant of the forces passes through the centre of the specimen. The surface of the lower platen of the machine was normal and remained normal during loading. The centre of the upper platen spherical seating was at the point of intersection of the vertical machine axis with the plane of the lower surface of the upper platen with a tolerance of $\pm 1 \mathrm{~mm}$. Each prism half is tested by loading its side faces using the mentioned equipment by centering the halves laterally to the platens of the machine within $\pm 0.5 \mathrm{~mm}$, and longitudinally such that the end face of the prism overhangs the platens or auxiliary plates by about $10 \mathrm{~mm}$. The load was increased smoothly at the rate of $2400 \pm 200 \mathrm{~mm} \mathrm{~N} / \mathrm{s}$ over the entire load application until Fracture.

Compressive strength $\mathrm{Rc}$ in megapascals is calculated from:

$$
\mathrm{Rc}=\mathrm{Fc} / 1600
$$

where

Rc: is the compressive strength, in megapascals;

Fc: is the maximum load at fracture;

1600: is the area of the platens $(40 \mathrm{~mm} \times 40 \mathrm{~mm})$.

\section{Results}

Table 1 lists the experimental results obtained in the present work. It includes in addition to compressive strength: fineness, consistence, density and water absorption. Chemical analyses of the six cement brands studied are listed in Table 2.

Figure 1 shows graphically the consistency of the studied cement types. Moqawem has the highest consistency and Alrajehi the lowest value.

Figure 2 shows the compressive strength of the six Jordanian cement mortars studied at 2, 7, and 28 day ages. Rasekh has the highest strength in the 3 ages and Shamaliyya the lowest.

Table 2 lists the progress of strength with time. It can be seen that the lowest $2 / 7$ days strength $(0.2)$ is obtained by Shamalliya. It is followed by is Moqawem and Rajehy (0.30 and 0.31), then Thabet (0.42), Bani (0.54), and finally Rasekh (0.67). Ratio of two to 28 day strength is arranged in ascending order as follows: Shamalliya (0.12), Rajehy (0.19), Moqawem (0.23), Thabet (0.33), 
Table 1. Physical, chemical and mechanical properties of the cements and their pastes.

\begin{tabular}{|c|c|c|c|c|c|c|}
\hline Tests & Thabet & Bany & Shamaliyya & Mokawim & Rasikh & Ragihy \\
\hline \multicolumn{7}{|l|}{ Fineness } \\
\hline$>125 \mu \mathrm{m}$ & 2.72 & 15.45 & 15.40 & 12.86 & 7.95 & 13.90 \\
\hline$>63 \mu \mathrm{m}$ & 9.71 & 22.02 & 9.67 & 25.10 & 57.10 & 19.60 \\
\hline $\operatorname{Pan}<63 \mu \mathrm{m}$ & 82.23 & 62.97 & 74.77 & 62.00 & 35.00 & 66.45 \\
\hline \multicolumn{7}{|c|}{ Specific Gravity g/cm ${ }^{3}$} \\
\hline 2-day & 1.97 & 2.01 & 1.96 & 2.00 & 1.94 & 1.94 \\
\hline 7-day & 2.04 & 2.04 & 1.98 & 2.04 & 2.02 & 2.03 \\
\hline 28-day & 2.00 & 1.79 & 1.99 & 2.02 & 2.08 & 2.04 \\
\hline 2-day & 9.81 & 9.44 & 10.39 & 9.73 & 7.89 & 9.88 \\
\hline 7-day & 8.83 & 8.76 & 8.90 & 8.80 & 7.52 & 9.43 \\
\hline 28-day & 8.28 & 8.81 & 9.51 & 8.72 & 8.86 & 8.80 \\
\hline \multicolumn{7}{|c|}{ Compressive Strength MPa } \\
\hline 2-day & 15.53 & 20.04 & 5.00 & 11.10 & 32.64 & 9.03 \\
\hline 7-day & 36.65 & 39.94 & 24.41 & 36.86 & 48.52 & 29.27 \\
\hline 28-day & 46.90 & 47.50 & 41.00 & 49.00 & 58.50 & 47.10 \\
\hline
\end{tabular}

Table 2. Relative increase of cement mortars.

\begin{tabular}{|c|c|c|c|c|c|c|}
\hline Cement & 2 day & 7 days & 28 days & 2/7 days & 2/28 day & 7/28 days \\
\hline Thabet & 15.53 & 36.65 & 46.9 & 0.42 & 0.33 & 0.78 \\
\hline Bani & 20.04 & 36.94 & 47.5 & 0.54 & 0.42 & 0.78 \\
\hline Shamal & 5 & 24.41 & 41 & 0.20 & 0.12 & 0.60 \\
\hline Moqawem & 11.1 & 36.86 & 49 & 0.30 & 0.23 & 0.75 \\
\hline Rasekh & 32.64 & 48.52 & 58.5 & 0.67 & 0.56 & 0.83 \\
\hline Rajehy & 9.03 & 29.27 & 47.7 & 0.31 & 0.19 & 0.61 \\
\hline
\end{tabular}

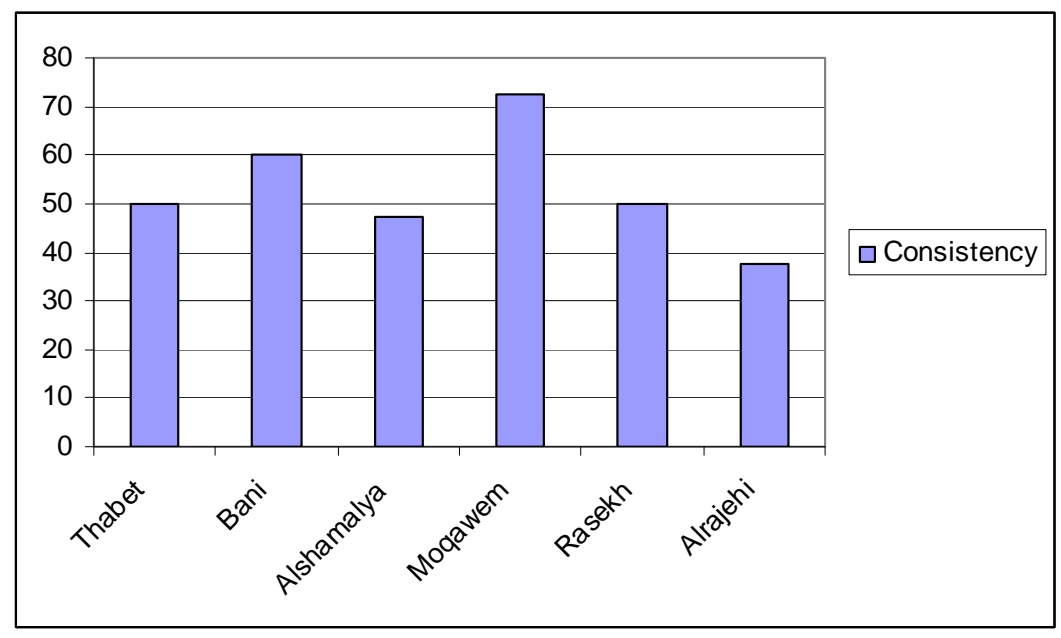

Figure 1. Average values for consistency of different types of cement. 
Bani (0.42) and Rasekh (0.56). Similarly, the 7/28 day ratio is lowest in Shamalliya and Rajehy $(0.60,0.61)$, intermediate in Moqawem, Thabet and Bani $(0.75,0.78$, 0.78), and highest in Rasekh (0.83).

Figure 3 shows an inverse linear relationship between compressive strength and water absorption. This can be simply explained by the fact the water absorption occurs through the presence of absorptive mineral species, such as some cement minerals, and/or through the filling of available pore space. It is a well known fact that the higher the percentage of the pore space, the weaker the material. It can also be seen that dispersion of data is lowest in 2 day mixes, intermediate in 7 day mixes and highest in 28 day mixes. Despite a general weak positive relation between density and strength, it is evident in Figure 4 that it is difficult to predict compressive strength from density alone. Figures 5 reveals that there is no clear relation between consistency and compressive strength of the cement mortars in the different ages. Plotting the less than 63 micron percentage against compressive strength (Figures 6-8), it is evidenced that the higher the percentage of the finer proportion the weaker the

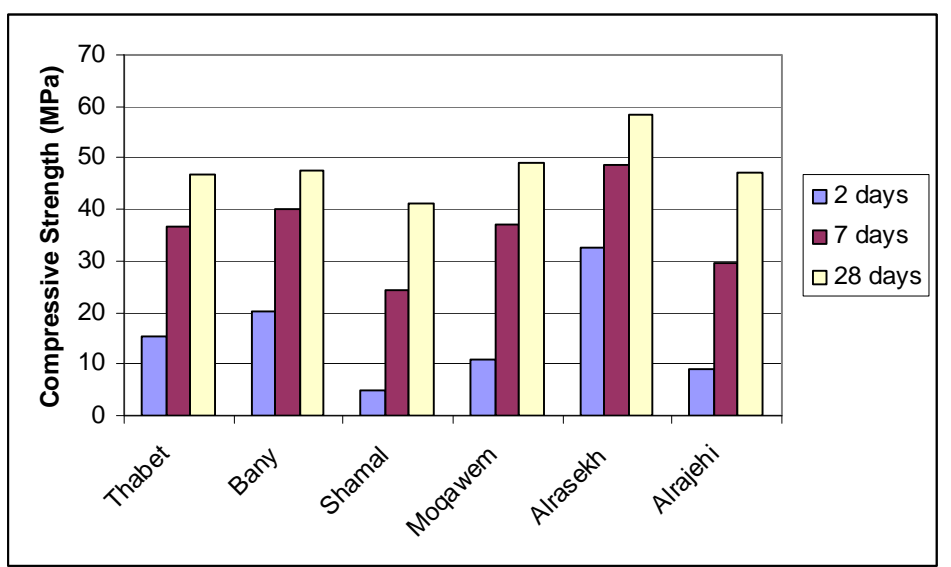

Figure 2. Compressive strengths (in MPa) for different types of cement mortars at ages of 2, 7 and 28 days.

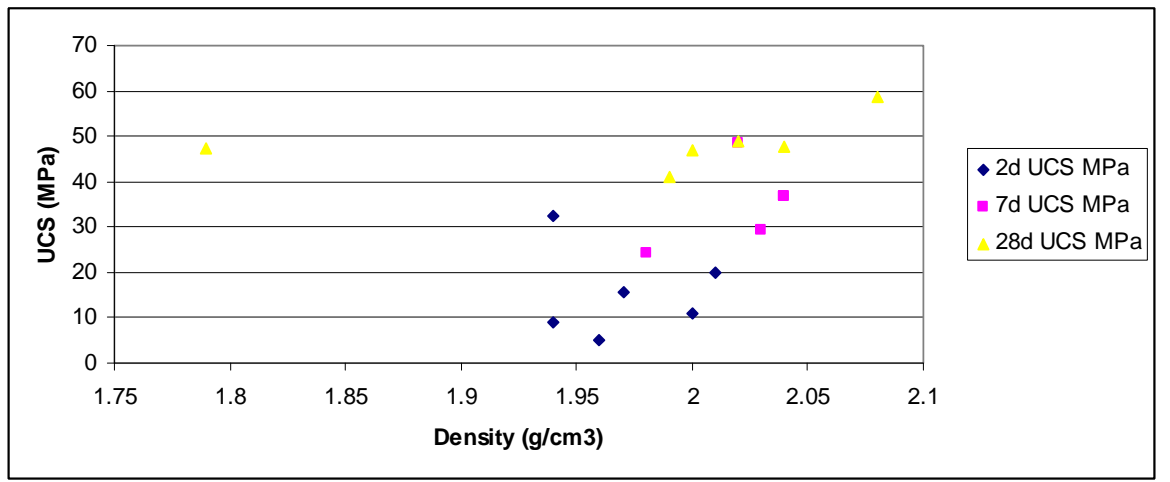

Figure 3. An inverse linear relationship between compressive strength and water absorption.

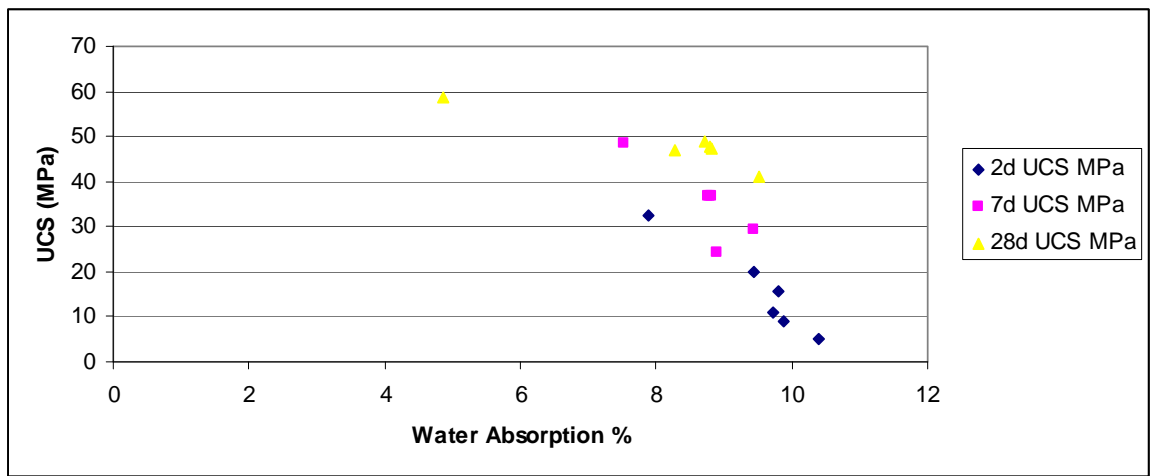

Figure 4. A positive weak linear relationship between compressive strength and density. 


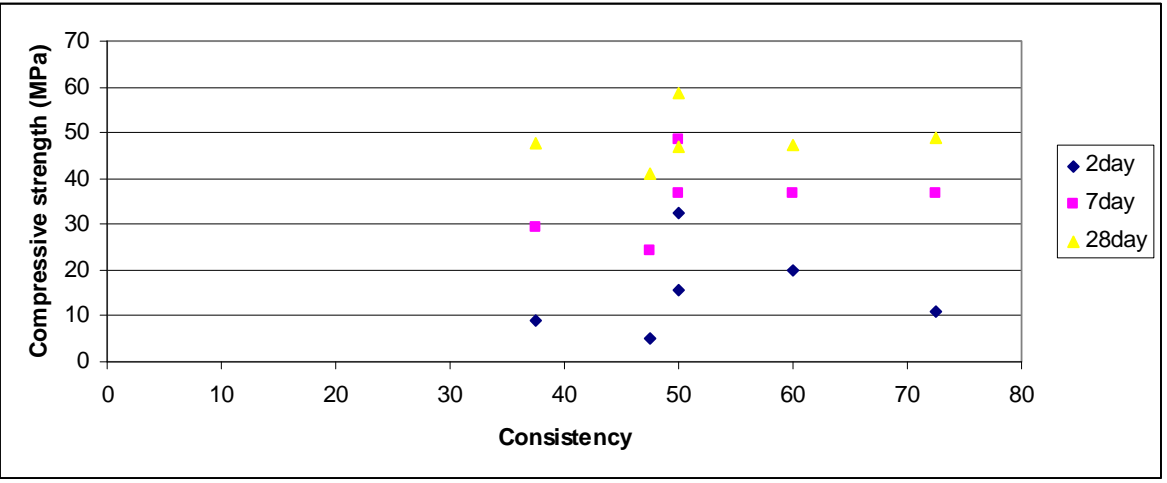

Figure 5. There is no clear relation between consistency and compressive strength.

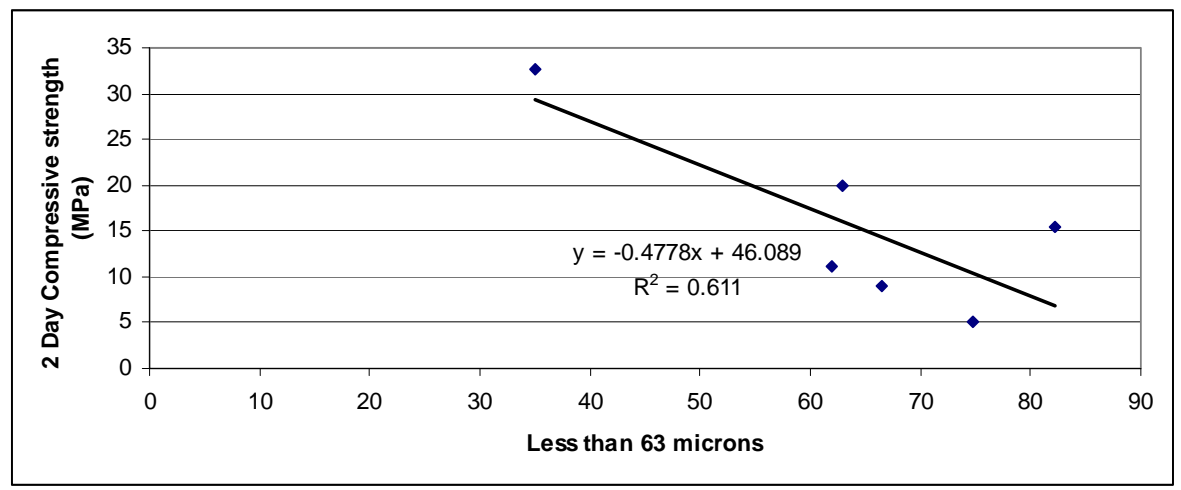

Figure 6. Inverse linear relation between less than 63 microns and 2 day compressive strength.

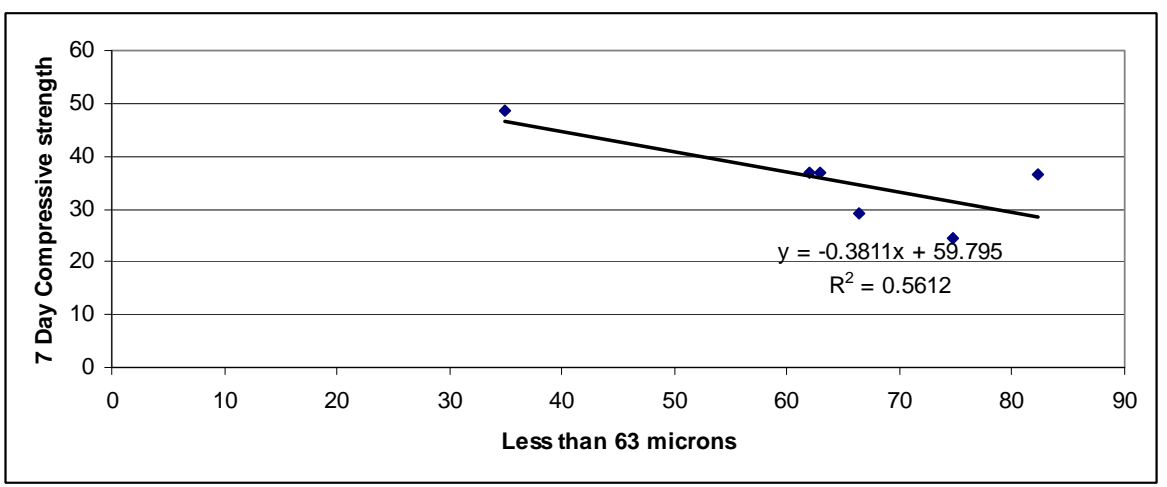

Figure 7. Inverse linear relation between less than 63 microns and 7 day compressive strength.

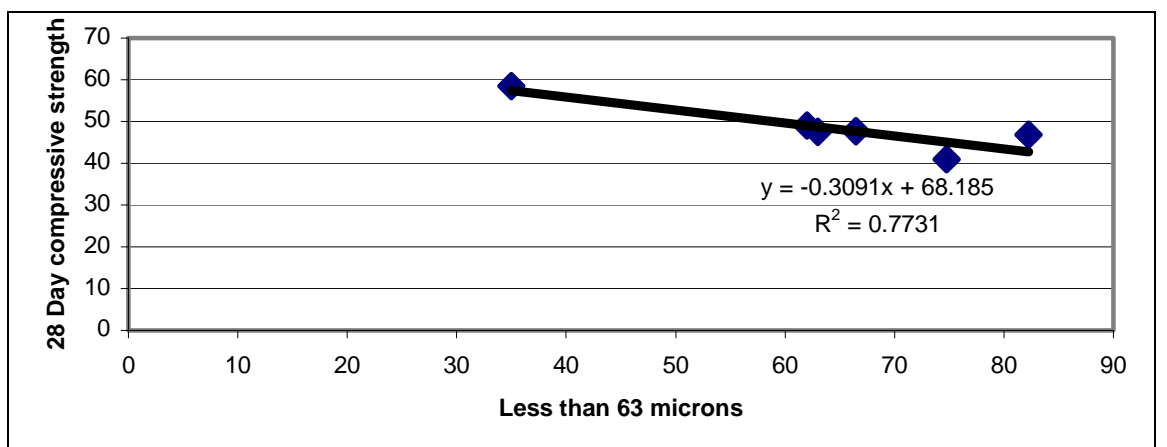

Figure 8. Inverse linear relation between less than 63 microns and 28 day compressive strength. 
mortar is. This is true for the all ages with the highest standard deviation occurring for 28 day age.

\section{Conclusions and Recommendations}

The following conclusions can be drawn out from the present work:

1) The compressive strength of mortars prepared from the six Jordanian cements has some variations between the different brands.

2) The rate of development of compressive strength of mortars with age may be different for the different cement brands.

3) An inverse linear relationship exists between compressive strength and water absorption.

4) With the small number of types of cement and specimens studied, it seems that there is no clear relation between consistency and compressive strength.

5) Positive weak linear relationship exists between compressive strength and density.

6) Inverse linear relations exist between less than 63 microns size fraction and strength.

To explain differences in compressive strength at different ages and using different cement brands, it is very important to identify the type and amount of cement mineral phases using concrete petrography and X-ray diffraction and fluorescence. It is highly recommended to repeat this work including more cement types and dif- ferent cement mixes.

\section{REFERENCES}

[1] ASTM C150-00, "Standard Specification for Portland Cement," ASTM International. www.astm.org

[2] ASTM C1157, "Standard Performance Specification for Hydraulic Cement," ASTM International. www.astm.org

[3] American Concrete Institute, "225R-99: Guide to the Selection and Use of Hydraulic Cements," Manual of Concrete Practice, 1999.

[4] G. J. Frohnsdorff, "Portland Cements, Blended Cements and Mortars," Concise Encyclopedia of Building and Construction Materials, 1990, pp. 495-504.

[5] A. M. Neville, "Properties of Concrete," 4th Edition, Prentice Hall, Upper Saddle River, 2000.

[6] F. Miller and T. Conway, "Use of Ground Granulated Blast Furnace Slag for Reduction of Expansion Due to Delayed Ettringite Formation," Cement and Concrete Aggregates, Vol. 25, No. 2, 2003, pp. 221-230.

[7] U. Noor, "Study of the Physical Parameters of Ordinary Portland Cement of Khyber Pakhtoon Khwa, Pakistan and Their Comparison with Pakistan Standard Specifications," Chemical Engineering Research Bulletin, Vol. 14, No. 1, 2010, pp. 7-10.

[8] EN-196-1, "Methods of Testing Cement—Determination of Strength,” European Standards EN-196-1, 2005. 